\title{
Neurological Improvement with Medical Cannabis in a Progressive Supranuclear Palsy Patient: A Case Report
}

\author{
Ana Gabriela Hounie ${ }^{a}$ Marco Agassiz Almeida Vasques ${ }^{b}$ \\ a Private Office, Psychiatry, São Paulo, Brazil; bivision of Research, Armed Forces Hospital, Brasília, Brazil
}

\section{Keywords}

Cannabis · Progressive palsy · Alzheimer's disease ·

Cannabidiol $\cdot$ Supranuclear

\begin{abstract}
Progressive supranuclear palsy (PSP) is a severe, debilitating, and often fatal disease resembling other neurodegenerative disorders, namely Alzheimer's (AD) and Parkinson's (PD) diseases, which have been successfully treated with cannabinoids. We herein report the case of a 71-year-old woman diagnosed with PSP, displaying severe impairment of motor and language functions which progressively improved after treatment with medical cannabis. Before treatment, the patient was unable to move her limbs, was fed soft food, and was unable to speak or move her eyes. The patient has regained horizontal eye movement, is able to walk with assistance, has returned to physiotherapy, started to eat solid food, and has had a remarkable improvement in her speech. The possible mechanisms of this improvement are discussed.

C) 2019 The Author(s)

Published by S. Karger AG, Basel
\end{abstract}

\section{Introduction}

Progressive supranuclear palsy (PSP) is a severe, debilitating, and often fatal disease that has no effective treatment to date. Its clinical and pathological features resemble other neurodegenerative disorders, such as Alzheimer's (AD) and Parkinson's (PD) diseases. The development of new therapies for neurodegenerative disorders has been the subject of intense research in recent years, with several experimental evidence suggesting the possible efficacy of cannabinoids, such as cannabidiol (CBD) and tetrahydrocannabinol (THC) [1]. We herein report the case of improvement in motor and language functions in a patient with PSP after the administration of medical cannabis.

\section{Case Report/Case Presentation}

A 71-year-old woman presented to the medical office with a history of 6 years of progressive gait disturbance, parkinsonism, and a severe language disturbance. She had lost the capacity to produce intelligible speech except for moans and unintelligible noises (dysarthria) and displayed ophthalmoplegia. She was also unable to walk and had rigidity of limbs.

Serum levels of folic acid, total calcium, creatinine, iron, ferritin, magnesium, phosphorus, and vitamin $\mathrm{B}_{12}$ were within normal ranges.

\begin{tabular}{ll}
\hline KARGER & $\begin{array}{l}\text { ○ } 2019 \text { The Author(s) } \\
\text { Published by S. Karger AG, Basel Openger }\end{array}$ \\
E-Mail karger@karger.com & This article is licensed under the Creative Commons Attribution- \\
www.karger.com/mca & $\begin{array}{l}\text { NonCommercial-NoDerivatives 4.0 International License (CC BY- } \\
\text { NC-ND) (http://www.karger.com/Services/OpenAccessLicense). } \\
\text { Usage and distribution for commercial purposes as well as any dis- } \\
\text { tribution of modified material requires written permission. }\end{array}$
\end{tabular}

Ana Gabriela Hounie

Rua Itapicuru 369

São Paulo, SP 05006000 (Brazil)

E-Mail ana.hounie@gmail.com 
A brain MRI was performed and showed (a) mesencephalonpontine disproportion characterized by marked reduction of the midbrain, with relative preservation of the pons associated with loss of the usual morphology of the midbrain, with dorsolateral concavity and reduction of anteroposterior diameter; (b) reduction of thalamic volume and narrowing of superior cerebellar peduncles, in addition to hypersignal of periaqueductal gray matter on FLAIR and T2WI; (c) signs of neurodegeneration with T2SEhyposignal mainly of the midbrain and posterolateral aspect of putamens, coinciding with volumetric reduction; (d) large cerebellar fissures, inferring some degree of cerebellar volumetric reduction; (e) enlargement of cortical and cerebellar sulci and brain fissures, predominantly in frontal and insular regions; (f) rare sparse foci with T2/FLAIR hyperintense signal without diffusion restriction on the white matter of the cerebral hemispheres, around the anterior horns and atria of the lateral ventricles, in the semioval nuclei/radiated crown and in the subcortical frontoparietal regions.

A full extract of cannabis oil with the approximate ratios of the main cannabinoids of $0.5 \%$ CBD, $2 \%$ THC, $10 \%$ CBDA (cannabidiolic acid), and 7\% THCA (tetrahydrocannabinolic acid) (approximately $11 \mathrm{mg} / \mathrm{mL}$ of CBD + CBDA and $9 \mathrm{mg} / \mathrm{mL}$ of $\mathrm{THC}+$ THCA) was prescribed, beginning with 2 sublingual drops at night and doubling the dose on a weekly basis. The oil was acquired by the patient's family from ABRACE (a non-profit organization founded by relatives of children with refractory epilepsy that benefited from cannabis oil and was conferred the right to grow, extract, and commercialize cannabis products in Brazil). There were no side effects attributable to the oil. After a 3-week period, an improvement in dysarthria was perceived. The patient started to articulate words, although still in an unintelligible manner, attempting to communicate. One week later, she improved word articulation and presented a slight return of gaze function. After 5 weeks of cannabis oil administration, her oral output was further improved, and the family and clinical staff were able to understand the words and the meaning of her speech. She also showed improvement in hand tremor and regained the ability to move her limbs. Finally, the patient was also able to stand on her feet and walk with assistance. Videos displaying the clinical picture and symptom improvement can be found in the online supplementary material (videos 1-5; for all online supplementary material, see www.karger.com/doi/10.1159/000503864).

\section{Discussion/Conclusion}

The case presented herein is probably the first report of PSP improvement in scientific literature. PSP is now considered a spectrum of motor and behavioral syndromes associated with a specific four-repeat (4R) tau neuropathology at autopsy. Two general types of tau dysfunction are thought to lead to disease: loss of normal tau function or toxic gain of tau function. Despite some research into how to deal with brain levels of toxic forms of tau or the compensation for loss of tau function [2], there is currently no effective treatment for PSP.
There is evidence of common toxic mechanisms in the etiopathogenesis of neurodegenerative diseases, mainly neuroinflammation, excitotoxicity, mitochondrial dysfunction, and reduced trophic support [3]. There has been substantial evidence of cognitive benefits with the association of $\Delta^{9}$-THC and CBD in experimental models of $\mathrm{AD}$, but the role of the endocannabinoid system in the pathophysiology of neurodegenerative disorders and its importance as a potential therapeutic target are beyond the scope of this report and were reviewed elsewhere [4]. Briefly, the endocannabinoid system modulates the release of several neurotransmitters such as dopamine, serotonin, noradrenaline, $\gamma$-aminobutyric acid (GABA), glutamate, acetylcholine (ACh), and endogenous opioids [5]. CBD and THC are the two most studied phytocannabinoids and represent potential therapeutic agents for several neuropsychiatric disorders, such as addiction, anxiety, mood, and psychotic disorders as well as movement disorders (PD, Tourette syndrome, spasticity of multiple sclerosis), refractory epilepsy, and chronic pain [6-13]. The efficacy of cannabinoids in neuropsychiatric disorders may be due to their multi-target drug profile and the ensuing modulation of neurotransmitter release by the endocannabinoid system $[14,15]$. CBD also decreases neuroinflammation through adenosine A2a receptor stimulation, exerts immunological modulation by reducing leukocyte transmigration and down-regulating the expression of vascular cell adhesion molecule-1, and reduces microglia activation and the expression of chemokine ligands 2 and 5 and interleukin 1 beta, among other effects [16]. In AD studies, $\mathrm{CBD}$ inhibited in vitro hyperphosphorylation of tau and reduced $\mathrm{A} \beta$ production by promoting amyloid precursor protein ubiquitination [17]. In addition, in vivo CBD treatment has been shown to reverse cognitive deficits in a double transgenic $\mathrm{AD}$ mouse model [18]. Anti-inflammatory and neuroprotective effects of CBD could be due to its ability to reduce the level of iNOS, GFAP, calcium binding protein B, and nuclear factor kappa-light-chain-enhancer of activated $B$ cells $(\mathrm{NF}-\kappa \mathrm{B})$. These actions may be partially mediated through the PPAR- $\gamma$ receptor [19]. Moreover, a prospective observational study found improvement in 10 severely demented patients regarding rigidity and behavioral problems treated with a CBD/THC combination [1].

Preliminary studies with CBD on PD have demonstrated that it reduces psychotic symptoms and REM sleep behavior disorder, and it could reverse catalepsy behavior in rodents, probably because of its action on the 5-HT1A receptor [20]. In vivo studies have shown that $\mathrm{CBD}$ has neuroprotective effects against MPP+ (a neuro-
Med Cannabis Cannabinoids 2019;2:65-68 DOI: $10.1159 / 000503864$
Hounie/Almeida Vasques 
toxic protein relevant to $\mathrm{PD}$ ), increasing mRNA levels of the antioxidant enzyme $\mathrm{Cu}, \mathrm{Zn}$-superoxide dismutase in substantia nigra, and preventing the depletion of dopamine and reduction in tyrosine hydroxylase activity in caudate-putamen [21]. CBD may also normalize glutamate homeostasis, reduce microglia activation, and promote neuritogenesis, which is not dependent or additive to nerve growth factor and might involve the activation of tropomyosin receptor kinase A (trkA) receptors and increased expression of axonal and synaptogenic proteins [22]. Moreover, an open-label report of 22 PD patients who used smoked cannabis evidenced improvement in tremor, rigidity, and bradykinesia [23]. Finally, THC exerted a neuroprotective effect against all toxins in a human cell model of PD attributable to activation of PPAR- $\gamma$ receptors [24].

CBD's multiple sites of action are both an advantage and a challenge for the daily clinical practice, as well as for research. Future research in animal models and observational studies in refractory patients or in patients with diseases with no specific treatment available are warranted. This new treatment might represent some hope to patients suffering from this fatal disease. Research of medical cannabis is still in its beginnings but should be encouraged, especially in refractory patients or those for whom there is no specific treatment

\section{Statement of Ethics}

This report was conducted ethically in accordance with the World Medical Association Declaration of Helsinki. The guardians of the patient have given their written informed consent to publish their case (including publication of images). The study protocol was approved by the Research Ethics Committee of the Armed Forces Hospital.

\section{Disclosure Statement}

The authors have no conflicts of interest to declare.

\section{Funding Sources}

There were no external funding sources to the study in the preparation of data or the manuscript.

\section{Author Contributions}

A.G.H. and M.A.A.V. fully participated in the conception, acquisition, analysis, and interpretation of data for the report, drafting the work and revising it critically for important intellectual content, and final approval of the version to be published.

\section{References}

1 Broers B, Patà Z, Mina A, Wampfler J, de Saussure C, Pautex S. Prescription of a THC/ CBD-based medication to patients with dementia: a pilot study in Geneva. Med Cannabis Cannabinoids. 2019;2(1):56-9.

2 Boxer AL, Yu JT, Golbe LI, Litvan I, Lang AE, Höglinger GU. Advances in progressive supranuclear palsy: new diagnostic criteria, biomarkers, and therapeutic approaches. Lancet Neurol. 2017 Jul;16(7):552-63.

3 Fagan SG, Campbell VA. The influence of cannabinoids on generic traits of neurodegeneration. Br J Pharmacol. 2014 Mar;171(6): 1347-60.

4 Basavarajappa BS, Shivakumar M, Joshi V, Subbanna S. Endocannabinoid system in neurodegenerative disorders. J Neurochem. 2017 Sep;142(5):624-48.

5 Cohen K, Weizman A, Weinstein A. Modulatory effects of cannabinoids on brain neurotransmission. Eur J Neurosci. 2019 Aug;50(3): 2322-45.

6 Boggs DL, Surti T, Gupta A, Gupta S, Niciu M, Pittman B, et al. The effects of cannabidiol (CBD) on cognition and symptoms in outpatients with chronic schizophrenia a randomized placebo controlled trial. Psychopharmacology (Berl). 2018 Jul;235(7):1923-32.
7 Friedman LK, Wongvravit JP. Anticonvulsant and Neuroprotective Effects of Cannabidiol During the Juvenile Period. J Neuropathol Exp Neurol. 2018 Oct;77(10):904-19.

8 Khan AA, Shekh-Ahmad T, Khalil A, Walker MC, Ali AB. Cannabidiol exerts antiepileptic effects by restoring hippocampal interneuron functions in a temporal lobe epilepsy model. Br J Pharmacol. 2018a Jun;175(11):2097-115.

9 Sales AJ, Fogaca MV, Sartim AG, Pereira VS, Wegener G, Guimaraes FS, et al. Cannabidiol Induces Rapid and Sustained Antidepressant-Like Effects Through Increased BDNF Signaling and Synaptogenesis in the Prefrontal Cortex. Mol Neurobiol. 2019 Feb;56(2): 1070-81.

10 Saletti PG, Tomaz C. Cannabidiol effects on prepulse inhibition in nonhuman primates. Rev Neurosci. 2018 Dec;30(1):95-105.

11 Shbiro L, Hen-Shoval D, Hazut N, Rapps K, Dar S, Zalsman G, et al. Effects of cannabidiol in males and females in two different rat models of depression. Physiol Behav. 2019 Mar; 201:59-63.

12 Solowij N, Broyd SJ, Beale C, Prick JA, Greenwood LM, van Hell H, et al. Therapeutic Effects of Prolonged Cannabidiol Treatment on Psychological Symptoms and Cognitive
Function in Regular Cannabis Users: A Pragmatic Open-Label Clinical Trial. Cannabis Cannabinoid Res. 2018 Mar;3(1):21-34.

13 Szaflarski JP, Bebin EM, Comi AM, Patel AD, Joshi C, Checketts D, et al.; CBD EAP study group. Long-term safety and treatment effects of cannabidiol in children and adults with treatment-resistant epilepsies: expanded access program results. Epilepsia. 2018 Aug; 59(8):1540-8.

14 Linge R, Jiménez-Sánchez L, Campa L, PilarCuéllar F, Vidal R, Pazos A, et al. Cannabidiol induces rapid-acting antidepressant-like effects and enhances cortical 5-HT/glutamate neurotransmission: role of 5-HT1A receptors. Neuropharmacology. 2016 Apr;103:1626.

15 Sonego AB, Prado DS, Vale GT, SepulvedaDiaz JE, Cunha TM, Tirapelli CR, et al. Cannabidiol prevents haloperidol-induced vacuos chewing movements and inflammatory changes in mice via PPAR $\gamma$ receptors. Brain Behav Immun. 2018 Nov;74:241-51.

16 Premoli M, Aria F, Bonini SA, Maccarinelli G, Gianoncelli A, Pina SD, et al. Cannabidiol: recent advances and new insights for neuropsychiatric disorders treatment. Life Sci. 2019 May;224:120-7.
Progressive Supranuclear Palsy

Improvement with Medical Cannabis
Med Cannabis Cannabinoids 2019;2:65-68 DOI: $10.1159 / 000503864$ 
17 Libro R, Diomede F, Scionti D, Piattelli A, Grassi G, Pollastro F, et al. Cannabidiol Modulates the Expression of Alzheimer's DiseaseRelated Genes in Mesenchymal Stem Cells. Int J Mol Sci. 2016 Dec;18(1):E26.

18 Watt G, Karl T. In vivo Evidence for Therapeutic Properties of Cannabidiol (CBD) for Alzheimer's Disease. Front Pharmacol. 2017 Feb;8:20.

19 Esposito G, Scuderi C, Valenza M, Togna GI, Latina V, De Filippis D, et al. Cannabidiol reduces $A \beta$-induced neuroinflammation and promotes hippocampal neurogenesis through PPAR $\gamma$ involvement. PLoS One. 2011;6(12): e28668.
20 More SV, Choi DK. Promising cannabinoidbased therapies for Parkinson's disease: motor symptoms to neuroprotection. Mol Neurodegener. $2015 \mathrm{Apr} ; 10(1): 17$

21 Peres FF, Lima AC, Hallak JE, Crippa JA, Silva RH, Abílio VC. Cannabidiol as a Promising Strategy to Treat and Prevent Movement Disorders? Front Pharmacol. 2018 May;9: 482.

22 Santos NA, Martins NM, Sisti FM, Fernandes LS, Ferreira RS, Queiroz RH, et al. The neuroprotection of cannabidiol against $\mathrm{MPP}^{+}$ induced toxicity in PC12 cells involves trkA receptors, upregulation of axonal and synaptic proteins, neuritogenesis, and might be relevant to Parkinson's disease. Toxicol In Vitro. 2015 Dec;30(1 1 Pt B):231-40.
23 Lotan I, Treves TA, Roditi Y, Djaldetti R. Cannabis (medical marijuana) treatment for motor and non-motor symptoms of Parkinson disease: an open-label observational study. Clin Neuropharmacol. 2014 Mar-Apr;37(2): 41-4.

24 Carroll CB, Zeissler ML, Hanemann CO, Zajicek JP. $\Delta^{9}$-tetrahydrocannabinol $\left(\Delta^{9}\right.$-THC) exerts a direct neuroprotective effect in a human cell culture model of Parkinson's disease. Neuropathol Appl Neurobiol. 2012 Oct; 38(6):535-47. 